\title{
Identification of Low Molecular Weight Proteins and Peptides from Schistosoma mekongi Worm, Egg and Infected Mouse Sera
}

\author{
Tipparat Thiangtrongjit ${ }^{1}$, Nattapon Simanon ${ }^{2}$, Poom Adisakwattana ${ }^{3}$, Yanin Limpanont ${ }^{4}$, \\ Phiraphol Chusongsang ${ }^{4}$, Yupa Chusongsang ${ }^{4}$ and Onrapak Reamtong ${ }^{1, *(1)}$
}

1 Department of Molecular Tropical Medicine and Genetics, Faculty of Tropical Medicine, Mahidol University, Bangkok 10400, Thailand; tipparat.thi@mahidol.ac.th

2 National Omics Center (NOC), National Science and Technology Development Agency, Pathum Thani 12120, Thailand; sn.nattapon@gmail.com

3 Department of Helminthology, Faculty of Tropical Medicine, Mahidol University, Bangkok 10400, Thailand; poom.adi@mahidol.ac.th

4 Department of Social and Environmental Medicine, Faculty of Tropical Medicine, Mahidol University, Bangkok 10400, Thailand; yanin.lim@mahidol.ac.th (Y.L.); phiraphol.chu@mahidol.ac.th (P.C.); yupa.chu@mahidol.ac.th (Y.C.)

* Correspondence: onrapak.rea@mahidol.ac.th; Tel.: +66-(0)-2306-9138; Fax: +66-(0)-2306-9139

check for

updates

Citation: Thiangtrongjit, T.; Simanon, N.; Adisakwattana, P.; Limpanont, Y.; Chusongsang, P.; Chusongsang, Y.; Reamtong, O. Identification of Low Molecular Weight Proteins and Peptides from Schistosoma mekongi Worm, Egg and Infected Mouse Sera. Biomolecules 2021, 11, 559. https:// doi.org/10.3390/biom11040559

Academic Editor: Nuno C. Santos

Received: 11 March 2021

Accepted: 8 April 2021

Published: 11 April 2021

Publisher's Note: MDPI stays neutral with regard to jurisdictional claims in published maps and institutional affiliations.

Copyright: (c) 2021 by the authors. Licensee MDPI, Basel, Switzerland. This article is an open access article distributed under the terms and conditions of the Creative Commons Attribution (CC BY) license (https:/ / creativecommons.org/licenses/by/ $4.0 /)$.

\begin{abstract}
Schistosoma mekongi is found in the lower Mekong river region and causes schistosomiasis Low sensitivity of diagnosis and development of drug resistance are problems to eliminate this disease. To develop novel therapies and diagnostics for S. mekongi, the basic molecular biology of this pathogen needs to be explored. Bioactive peptides have been reported in several worms and play important roles in biological functions. Limited information is available on the S. mekongi peptidome. Therefore, this study aimed to identify S. mekongi peptides using in silico transcriptome mining and mass spectrometry approaches. Schistosoma peptide components were identified in adult worms, eggs, and infected mouse sera. Thirteen neuropeptide families were identified using in silico predictions from in-house transcriptomic databases of adult $S$. mekongi worms. Using mass spectrometry approaches, 118 peptides (from 54 precursor proteins) and 194 peptides (from 86 precursor proteins) were identified from adult worms and eggs, respectively. Importantly, eight unique peptides of the $S$. mekongi ubiquitin thioesterase, trabid, were identified in infected mouse sera 14, 28, and 56 days after infection. This protein may be a potential target for diagnosis of schistosomiasis. The S. mekongi peptide profiles determined in this study could be used for further drug and diagnostic development.
\end{abstract}

Keywords: peptide; Schistosoma mekongi; biomarker

\section{Introduction}

Schistosoma mekongi is a causative agent of schistosomiasis in the Mekong region. The Lao People's Democratic Republic and Cambodia are endemic areas of this disease [1]. In 2017, all countries with endemic schistosomiasis in the Western Pacific Region aimed to achieve interruption of transmission by 2025 and to eliminate transmission by 2030 [2]. The World Health Organization recommends the Kato Katz test as the gold standard for diagnosis of Mekong schistosomiasis. Because this method relies on egg detection in stool using a microscope, it has low sensitivity for mild infections. S. mekongi infection generally yields low egg intensity. In some patients, egg shading in feces cannot be observed, and only rectal snipping (a more invasive technique) is able to demonstrate Mekong schistosomiasis [3]. To accomplish the goal of elimination and for effective S. mekongi surveillance monitoring, knowledge of the molecular biology of the organism and new interventions for disease control are required.

Bioactive peptides have been reported in many worm species such as Caenorhabditis elegans [4] and Ascaris suum [5]. These peptides contribute to diverse functions and biological 
processes. Recently, high-throughput technologies have been developed that allow the discovery of bioactive peptides in pathogenic organisms. In schistosomes, a dermaseptin-like peptide has been identified in acetabular glands of cercariae and has demonstrated antimicrobial, hemolytic, and immunomodulatory properties [6]. A S. mansoni neuropeptideI/Lamide-was identified in S. mansoni larval and adult worms. However, no effects of the peptide on aberrant mobility or morphological phenotypes were detected by knockdown experiments [7]. Prohormones involved in reproductive biology were identified using a genome-wide technique in S. mansoni and S. japonicum [8]. In addition to identification of peptides from parasites, identification of novel markers of $S$. mansoni infection from urine samples has been attempted. Ninety-three percent of infected children could be classified correctly based on their urinary peptide profiles [9]. Hemoglobin-derived peptides were identified in the urine of S. haematobium-infected patients even when microhematuria tests were negative [10].

Currently, no information on $S$. mekongi bioactive peptides is available. In this study, the low molecular weight proteins and peptides of $S$. mekongi worm, egg, and infected mouse sera were explored. Because the $S$. mekongi transcriptome is available and was previously published by our group [11], this dataset was used to provide the information of peptides in S. mekongi using data mining and proteomic approach. Bioinformatic analyses were applied for assessing the bioactivity of the $S$. mekongi peptidome. The worm and egg peptides are essential for understanding the $S$. mekongi molecular biology, and they also facilitate the schistosome drug development. Moreover, the S. mekongi circulating peptides in the infected sera are useful for diagnosis development. This dataset may lead to the development of interventions for the diagnosis and treatment of Mekong schistosomiasis.

\section{Methods}

\subsection{Identification of Peptidomes from S. mekongi Transcriptome Data}

The S. mekongi adult worm transcriptome dataset [11] was used to identify proteins containing $\leq 280$ amino acids and with molecular weights of $\leq 30 \mathrm{kDa}$. The neurofunctions of these proteins were predicted by annotation and neuropeptide domain recognition using the Neuropep database [12]. Non-neuropeptides were further classified by gene ontology using Blast2GO software. The bioactivities of peptides of unknown function were predicted using PeptideRanker software [13]. The significance score threshold was set at 0.8.

\subsection{Preparation of Worms, Eggs, and Infected Mouse Sera}

All animal procedures were approved by the Faculty of Tropical Medicine Animal Care and Use Committee (FTM-ACUC), Mahidol University (approval number FTMACUC No. 008/2016). All experiments were performed in accordance with relevant guidelines and regulations. Eight-week-old female ICR mice (25-35 g) were used in this experiment. S. mekongi cercariae were prepared from Neotricula aperta snails without any pre-treatment. ICR mice $(\mathrm{N}=6)$ were anesthetized with $\mathrm{Nembutal}^{\circledR}$ (Pentobarbital) 40-60 mg/kg intraperitoneal injection with tuberculin syringe and 26-gauge needle. The mice were exposed with cercariae by abdominal exposure. For a mouse, thirty cercariae were counted under microscope and gently applied to the mouse abdomen by hairpin. Sera were collected pre- and post-infection (days 14, 28, and 56). After 6-8 weeks, infected mice were sacrificed and dissected. Adult worms were flushed out by vascular perfusion using $0.85 \%$ sodium chloride. The perfusion solution was transferred to a sedimentation cone. Adult worms settled at the bottom of the cone were collected. Mouse livers and intestines were homogenized in $0.85 \%$ sodium chloride. Homogenates were sequentially passed through 80,120,160, and 260 mesh stainless steel sieves to separate S. mekongi eggs from liver and intestinal tissue. The eggs were washed three times with NSS and stored in liquid nitrogen until used. 


\subsection{Peptide Preparation}

S. mekongi adult worms and eggs were dissolved in $8 \mathrm{M}$ urea and sonicated on ice for $10 \mathrm{~s}$. The lysates were centrifuged for $20 \mathrm{~min}$ at $20,000 \mathrm{~g}, 4^{\circ} \mathrm{C}$. The supernatants and mouse sera were individually filtered using Amicon Ultra $0.5 \mathrm{~mL}$ centrifugal filters with a molecular weight cutoff of $30 \mathrm{kDa}$ (Millipore, Darmstadt, Germany) by centrifugation for $20 \mathrm{~min}$ at $15,000 \times \mathrm{g}, 4^{\circ} \mathrm{C}$. The flowthrough peptides were enriched using reverse phase C18 ZipTip chromatography (Millipore). The tips were pre-rinsed with $50 \%$ acetonitrile then equilibrated with $0.1 \%$ trifluoroacetic acid (TFA). The samples were loaded onto the zips and washed with $0.1 \%$ TFA, $80 \%$ acetonitrile. The peptides were dried using a speed vacuum (Tomy, Tokyo, Japan).

\subsection{Mass spectrometry}

The peptide solution was resuspended in $0.1 \%$ formic acid and then injected on an UltiMate $^{\mathrm{TM}} 3000$ nano-LC system (Dionex, Surrey, UK). The column was an Acclaim PepMap RSLC $75 \mu \mathrm{m} \times 15 \mathrm{~cm}$ nanoviper C18 with a $2 \mu \mathrm{m}$ particle size and a $100 \AA$ pore size (Thermo Scientific, Waltham, MA, USA). The LC system was coupled with a MicroToF Q II mass spectrometer (Bruker; Bremen, Germany). Mass ranges were acquired at 500-3500 m/z. MASCOT search engine 2.3 (Matrix Science, Chicago, IL, USA) was used for data analysis. An in-house generated S. mekongi transcriptomic database was used for searching. The search parameters were as follows: one missed cleavage, trypsin digestion, $0.8 \mathrm{Da}$ peptide tolerance, \pm 0.8 fragment mass tolerance, acetyl (protein N-terminus), amidated (protein C-terminus), Gln $\rightarrow$ pyro-Glu (N-terminal Glu), Glu- $\rightarrow$ pyro-Glu (Nterminal Glu), oxidation (Met), and variable modifications. The significance threshold was 0.05 .

\subsection{Bioinformatic Analysis}

The protein sequence of the $S$. mekongi ubiquitin thioesterase trabid was retrieved from an in-house transcriptome database. Other ubiquitin thioesterase trabid sequences, including TNN19375.1 (S. japonicum), XP_018651129.1 (S. mansoni), XP_012798773.1 (S. haematobium), TGZ66416.1 (Opisthorchis felineus), GAA33082.2 (Clonorchis sinensis), OON19543.1 (Opisthorchis viverrini), XP_006508032.1 (M. musculus), and XP_006717970.1 (H. sapiens), were retrieved from the nonredundant protein sequence database of the National Center for Biotechnology Information (NCBI). All sequence alignments and calculations of percent identity were performed using Clustal Omega software.

\section{Results}

\subsection{In Silico Prediction of S. mekongi Peptidomes Using Transcriptome Mining}

Low molecular weight proteins and peptides with $\leq 30 \mathrm{kDa}$ molecular weights and $\leq 280$ amino acids in length were retrieved from the S. mekongi adult worm transcriptome dataset. A total of 8440 sequences were obtained, and these sequences were further investigated for their biological functions following the workflow in Figure 1. Among them, 17\% (1430 sequences), 41\% (3469 sequences), 3\% (225 sequences), and 39\% (3316 sequences) were predicted as neuropeptides, peptides of other gene ontologies, bioactive peptides, and peptides of unknown function, respectively (Figure 2, Supplementary Dataset 1). Neuropeptides could be further classified into 13 families according to a neuropeptide database as shown in Table 1. YGGW-amide related peptide, thyrotropin-releasing hormone (TRH), and vasopressin/oxytocin were the major neuropeptide families of S. mekongi adult worms. FMRFamide related peptide, kisspeptin 1 (KiSS1), opioid peptide, LWamide neuropeptide, arthropod hyperglycemic hormone/molt-inhibiting hormone/gonad-inhibiting hormone/vitellogenesis-inhibiting hormone (CHH/MIH/GIH/VIH hormone), serpin, egg-laying hormone (ELH), pyrokinin, neurotensin, and neuropeptide $\mathrm{Y}$ family peptides were also observed in S. mekongi. Non-neuropeptides were further subjected to gene ontology classification using multilevel analysis. A total of 7013 peptides demonstrated gene ontologies. The top 20 classes according to biological process, molecular function, 
and cellular component terms are shown in Figure 3. DNA integration, translation, and regulation of transcription were the major classes in biological process terms. Nucleic acid binding, ATP binding, and RNA-directed DNA polymerase activity were the main classes in molecular process terms. Integral components of membrane, nucleus, and cytoplasm were the dominant classes in cellular process terms. The bioactivities of peptides whose functions could not be specified by gene ontology were predicted using PeptideRanker. A total of 225 peptides had scores more than 0.8 , indicating bioactive properties.

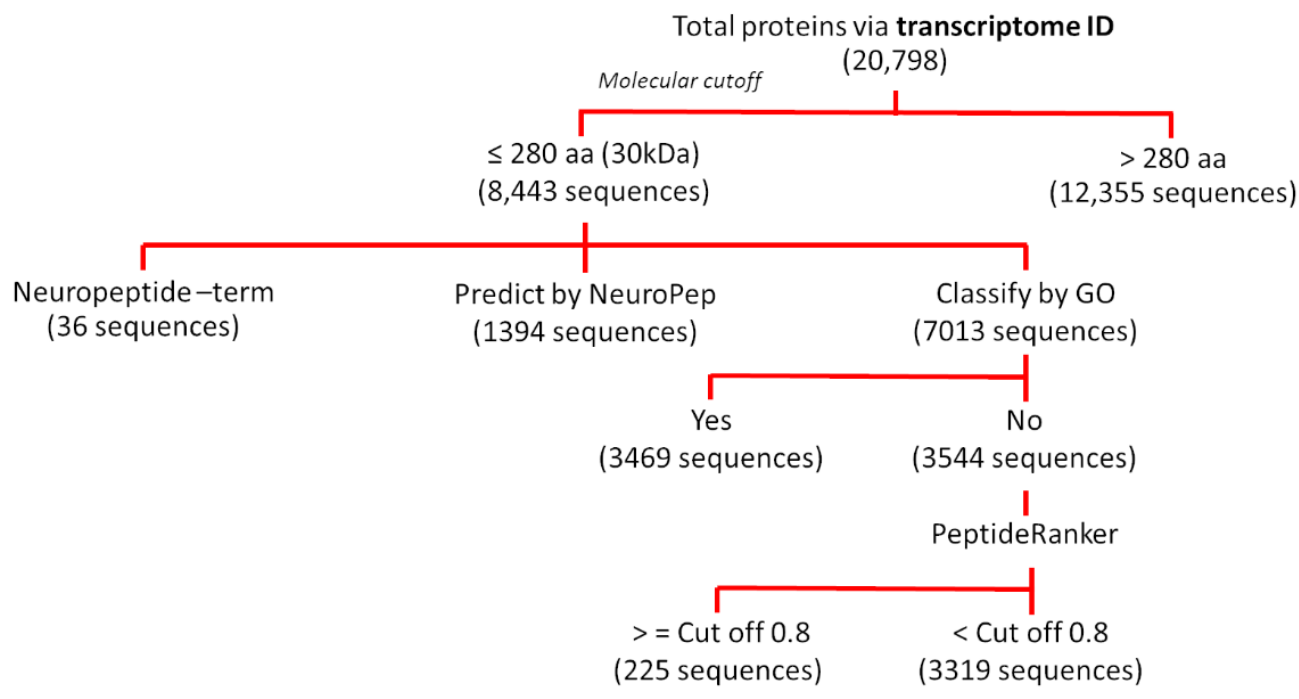

Figure 1. In silico transcriptome mining workflow for S. mekongi peptidome prediction.

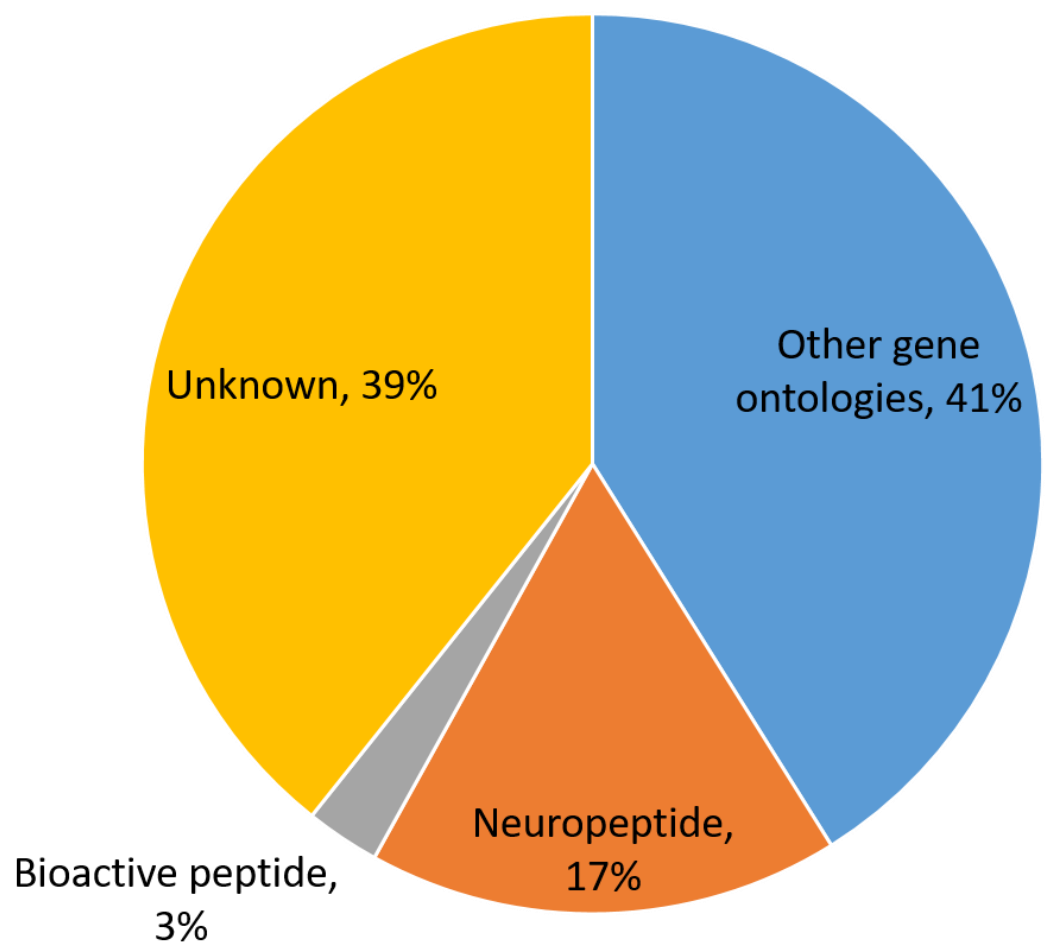

Figure 2. Classification of S. mekongi peptidome identified by mining approach. 
Table 1. Family of S. mekongi neuropeptides.

\begin{tabular}{cc}
\hline Family & Sequences \\
\hline YGGW-amide related peptide & 474 \\
TRH & 265 \\
Vasopressin/oxytocin & 177 \\
FMRFamide related peptide & 74 \\
KISS1 & 26 \\
Opioid & 18 \\
LWamide neuropeptide & 14 \\
Arthropod CHH/MIH/GIH/VIH hormone & 11 \\
Serpin & 10 \\
Molluscan ELH & 7 \\
Pyrokinin & 3 \\
Neurotensin & 1 \\
NPY & 1 \\
N/A & 491 \\
\hline
\end{tabular}

\subsection{Characterization of S. mekongi Adult Worm and Egg Peptidomes by Mass Spectrometry}

Peptides from S. mekongi adult worms and eggs were separated by filtration ( $30 \mathrm{kDa})$, purified using stagetip C18 resin, and then analyzed by mass spectrometry. A total of 118 peptides (from 54 precursor proteins) and 194 peptides (from 86 precursor proteins) were identified from adult worms and eggs, respectively (Figure 4 and Supplementary Dataset 2). Only two peptides were observed in both samples: a peptide derived from histone chaperone anti-silencing function protein 1 homolog (DKLDSSNFCENQ) and a peptide derived from an uncharacterized protein (FGQPMMHSGMP). The precursor proteins of these two peptides were not related neuropeptides. The top $10 \mathrm{~S}$. mekongi peptides from adult worms and eggs ranked by peptide scores are shown in Supplementary Dataset 3. Peptides NGFSSITTFNVSSSYSKNSNDQDY, KPINAETQFCVSSSVMNNEIFSSL, and SPSQVLFILFMSV demonstrated the highest scores in S. mekongi adult worms; their precursor proteins were ethanolamine kinase 1, uncharacterized protein, and AP-3 complex subunit delta-1, respectively. Peptides VNCIESEFL, MHSQHHAKPNVIDKDPDVR, and DNIKKLKTQMEMNMKEQN were the top scoring peptides in S. mekongi eggs; their precursor proteins were PDZ domain protein, fatty acid desaturase 1, and an uncharacterized protein, respectively. No neuropeptides were observed in the top 10 ranked peptides from adult worms or eggs. SPSQVLFILFMSV and GFGGHPFSSSG were predicted as bioactive peptides in S. mekongi worms and eggs, respectively, using PeptideRanker software with a 0.5 threshold. These peptides may contribute to schistosome molecular function. Further analysis of whole peptides identified by mass spectrometry revealed 17 and 31 proteins identified as precursors of $S$. mekongi neuropeptides in adult worms and eggs, respectively (Supplementary Dataset 4 and 5). The EAAVVSRQHPVKGEC and VSTGGG neuropeptides (QHP and GGG related neuropeptides, respectively) were identified by mass spectrometry from S. mekongi adult worms. The QHLSMNPLVESF and QVLMPLGYKVISR neuropeptides (QHL and PLG related neuropeptides, respectively) were identified by mass spectrometry from $S$. mekongi eggs. The amino acid positions of neuropeptide regions within precursor protein sequences were identified using NeuroPep, a neuropeptide software (http:/ / isyslab.info (accessed on 11 April 2021).). Neuropeptides consisting of TKP, PLG and GGG sequences were predominantly found in S. mekongi adult worms. Neuropeptides containing GGG, YRI and QHL sequences were mainly observed in S. mekongi eggs. 
Top-20, Biological process

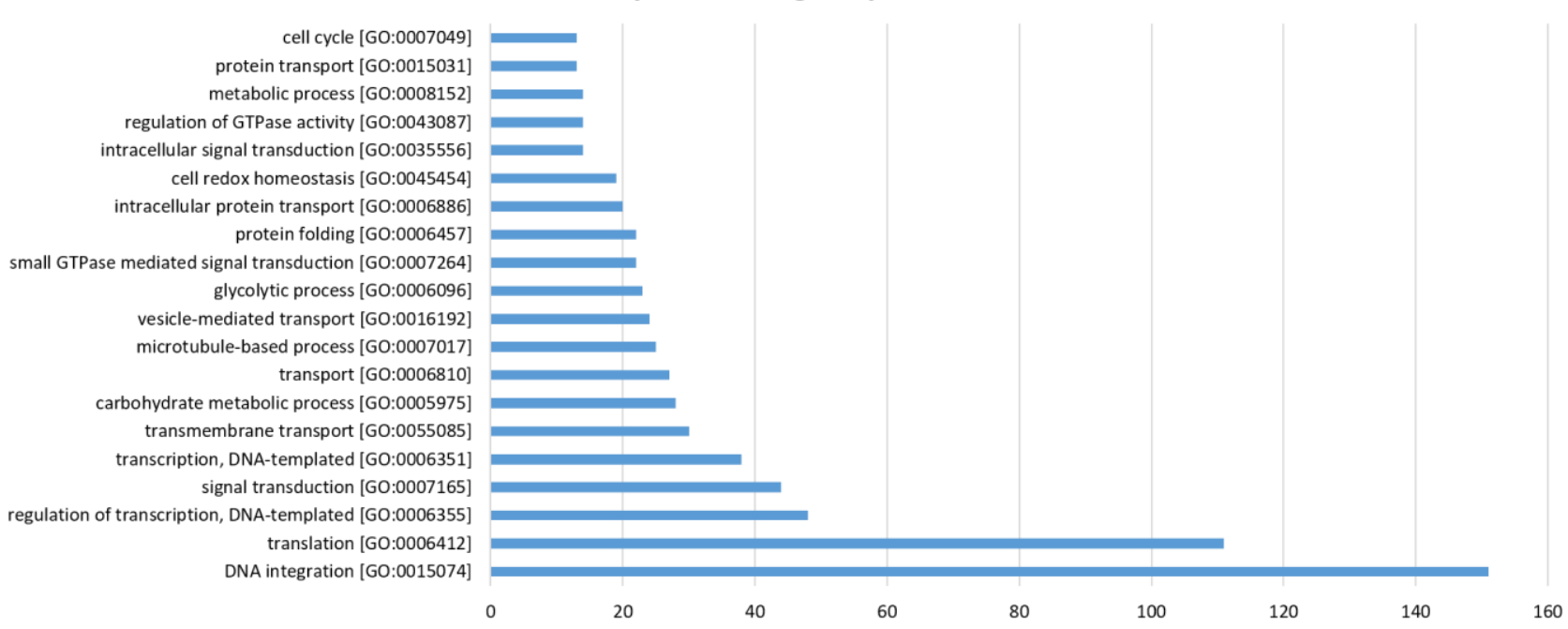

Top-20, Molecular function

transcription factor activity, sequence-specific DNA binding [GO:0003700] catalytic activity [GO:0003824] protein kinase activity [GO:0004672] transferase activity, transferring acyl groups [GO:0016746] sequence-specific DNA binding [GO:0043565] G-protein coupled receptor activity [GO:0004930] ligase activity [GO:0016874] aspartic-type endopeptidase activity [GO:0004190] GTPase activity [GO:0003924] metal ion binding [GO:0046872] endonuclease activity [GO:0004519] DNA binding [GO:0003677] GTP binding [GO:0005525] calcium ion binding [GO:0005509] RNA binding [GO:0003723] structural constituent of ribosome [GO:0003735] zinc ion binding [GO:0008270] RNA-directed DNA polymerase activity [GO:0003964] ATP binding [GO:0005524] nucleic acid binding [GO:0003676]

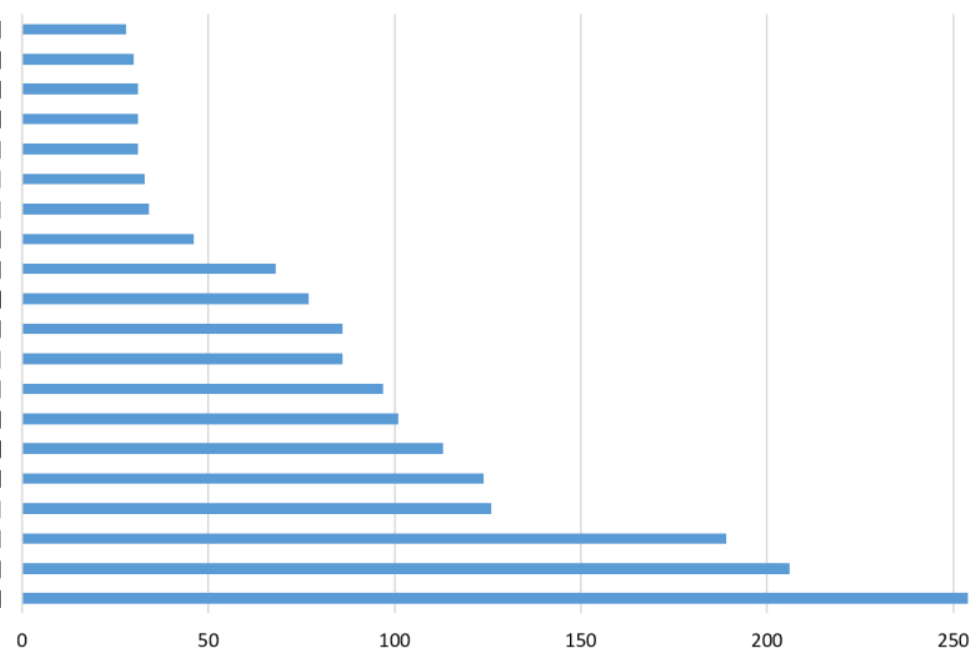

Top-20, Cellular component

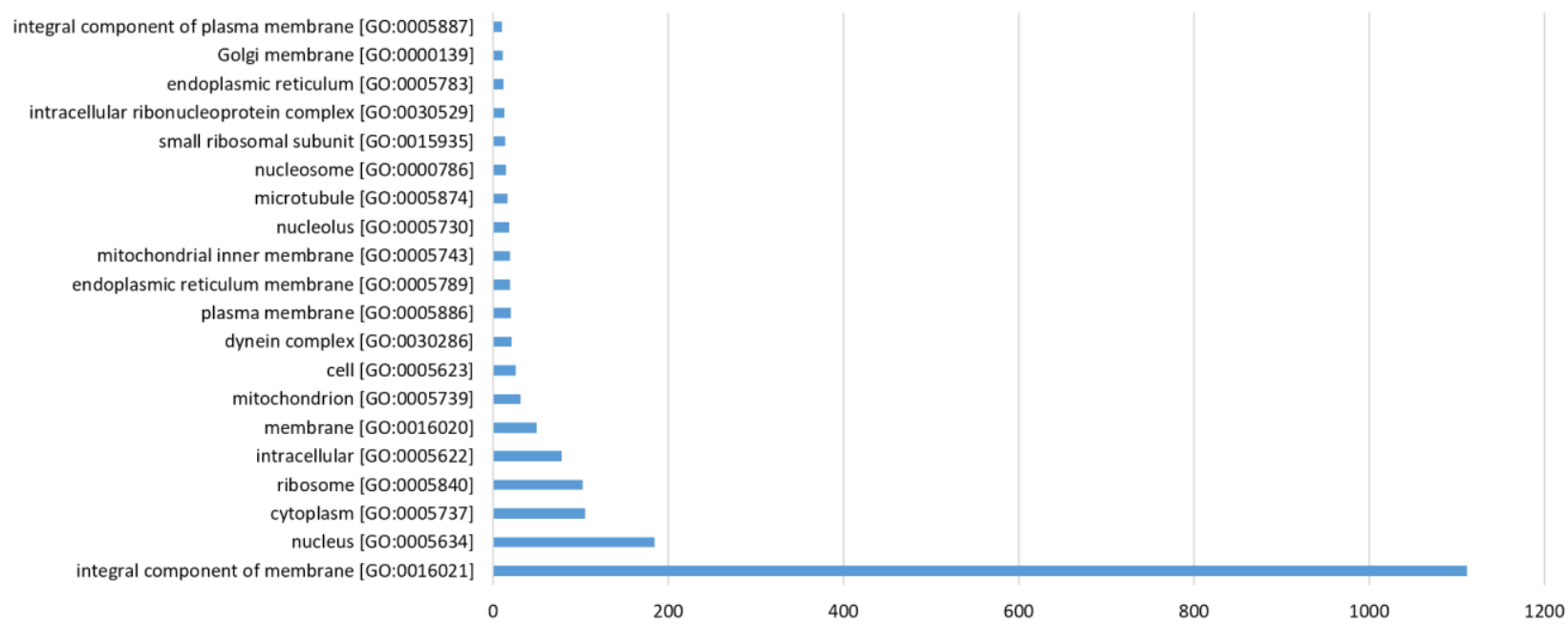

Figure 3. Top-10 most significant gene ontology classification of $S$. mekongi peptidome identified by mining approach. 


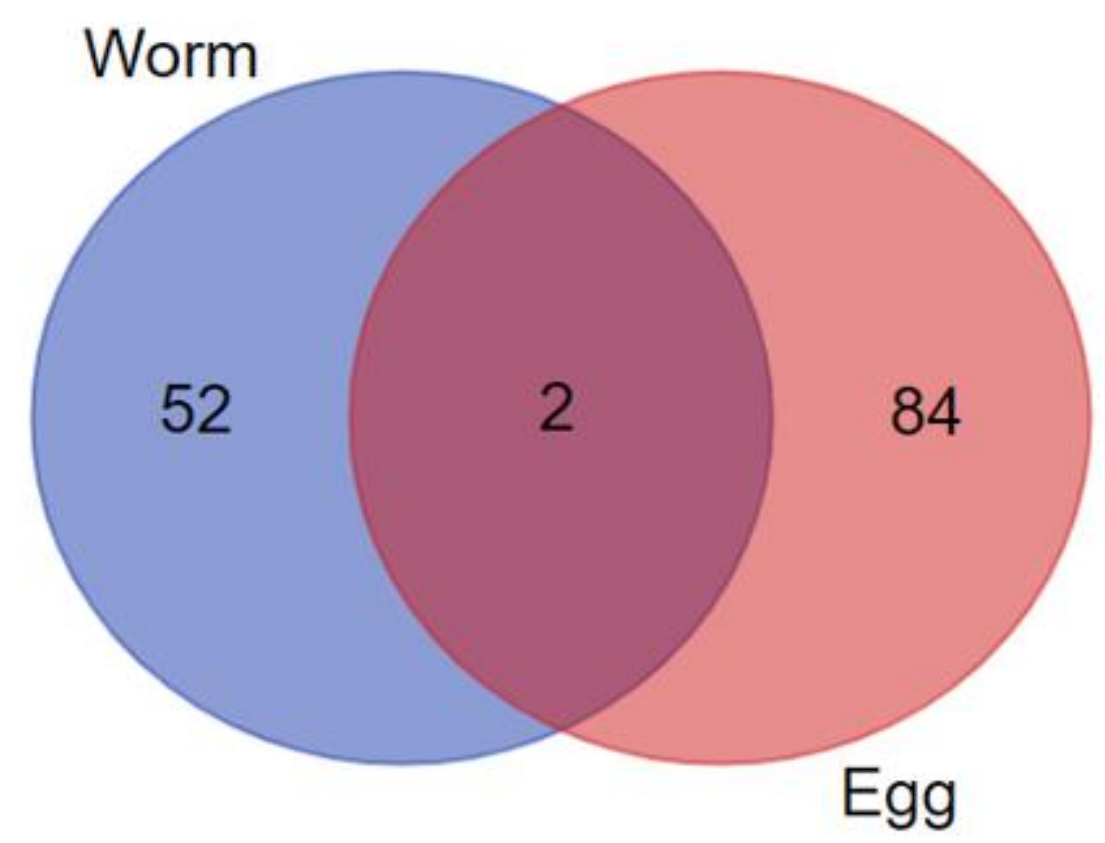

Figure 4. Venn diagram of $S$. mekongi adult worm and egg peptidomes identified by mass spectrometry.

\subsection{Identification of S. mekongi Peptides in Infected Mouse Sera}

Peptides were identified from uninfected mouse sera (Day 0) and infected mouse sera (Day 14, Day 28, and Day 56 after infection). Peptide identification was performed by mass spectrometry analysis and by searching against the in-house S. mekongi transcriptomic dataset. Any peptides that were identified from uninfected mouse sera were subtracted from those identified from infected mouse sera. A total of 385 peptides (from 120 precursor proteins), 288 peptides (from 90 precursor proteins), and 349 peptides (from 106 precursor proteins) were identified in infected mouse sera 14,28 , and 56 days after infection, respectively (Figure 5). The top $20 \mathrm{~S}$. mekongi peptides identified from infected mouse sera are presented in Table 2. The S. mekongi peptide profiles in mouse sera 14, 28, and 56 days after infection were dissimilar. These data could be useful for the development of diagnostics to distinguish the early, middle, and late stages of schistosoma infection. Peptides SQFQPHFVVDTMSKGA, QWANLMEKIQASVATNPIITPVAQENQ, and NEVHTMLGQSTEEIRA had the highest scores 14, 28 and 56 days after infection. The precursor protein of the formermost peptide was a cation-transporting ATPase worm, while the precursors of the other two peptides were uncharacterized proteins. S. mekongi peptides of the ubiquitin thioesterase trabid (molecular weight 103,015 Da) were consistently observed at 14, 28 and 56 days after infection. The identified peptide sequences of $S$. mekongi ubiquitin thioesterase trabid are presented in Table 3. Eight peptides were specific to S. mekongi compared with a Mus musculus protein sequence database. The protein sequence of the $S$. mekongi ubiquitin thioesterase trabid was compared with homologs in S. japonicum, S. mansoni, S. haematobium and Homo sapiens. For other helminths, proteins from Opisthorchis felineus, Clonorchis sinensis and Opisthorchis viverrini which showed the highest percent identity to the $S$. mekongi ubiquitin thioesterase trabid were also used for the comparison. Percent sequence identity is shown in Table 4 . The sequence of the ubiquitin thioesterase trabid was conserved among schistosomal species. The percent identities among schistosomal trabid sequences ranged between $81.12 \%$ and $93.24 \%$. The sequences of the mouse and human homologs differed substantially. The percent identities between schistosome and human trabid sequences ranged between $39.52 \%$ and $40.22 \%$. In addition, percent identities between schistosome and other helminths ranged between $54.18 \%$ and $56.23 \%$. Therefore, the schistosomal ubiquitin thioesterase trabid could represent a good candidate for development of diagnostics. 


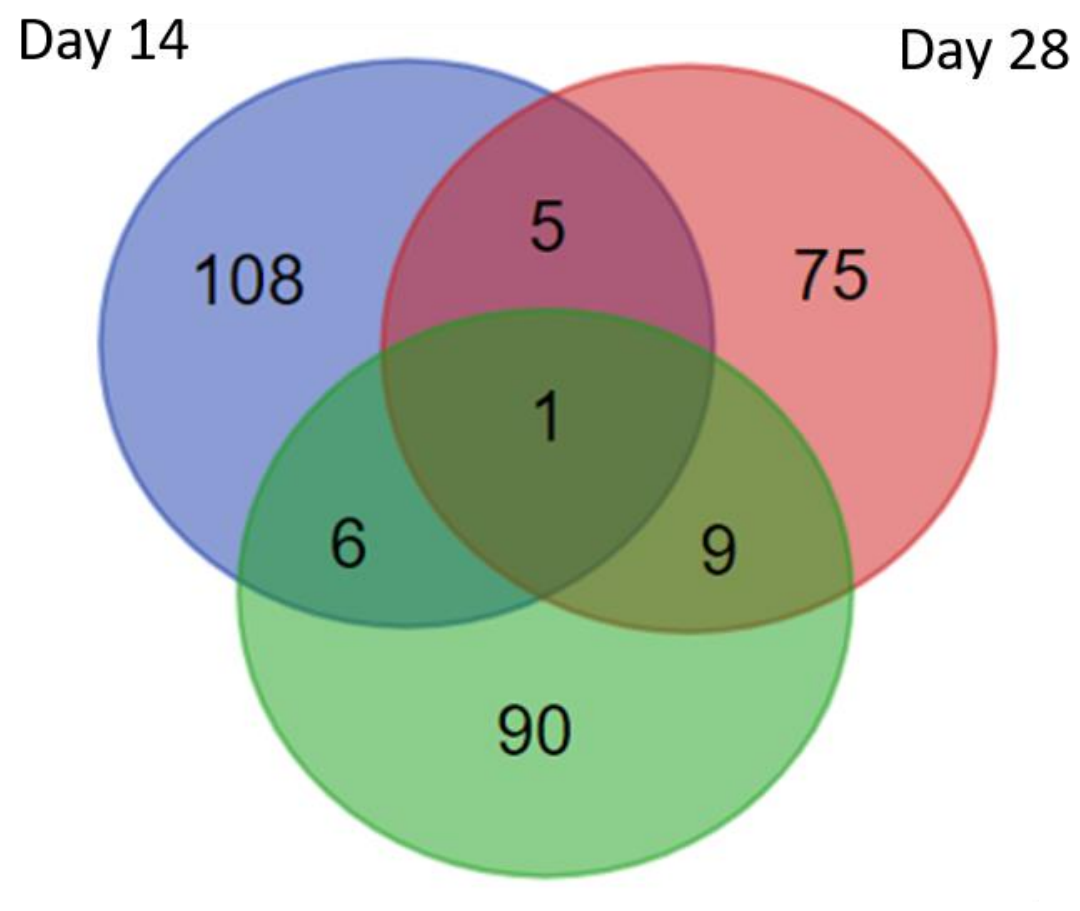

\section{Day 56}

Figure 5. Venn diagram of $S$. mekongi peptides in mouse sera collected pre- and post-infection (days 14,28 and 56) identified by mass spectrometry.

Table 2. Top 20 S. mekongi peptides identified from infected mouse serum at 14, 28 and 56 days after infection ranked by peptide scores.

\begin{tabular}{|c|c|c|c|c|c|}
\hline No. & Precursor Protein & Score & E-Value & Peptide & Modification \\
\hline \multicolumn{6}{|c|}{ D14 } \\
\hline 1 & Putative cation-transporting ATPase worm & 56.76 & 0.00014 & SQFQPHFVVDTMSKGA & Oxidation (M) \\
\hline 2 & Cyclin-dependent kinase 14 & 53.61 & 0.00083 & STPLSLVNM & Oxidation (M) \\
\hline 3 & Uncharacterized protein & 53.46 & 0.00027 & VVYPWTQRYFDSF & \\
\hline 4 & Uncharacterized protein & 53.35 & 0.00011 & VITSKY & \\
\hline 5 & Mitogen-activated protein kinase 15 & 52.79 & 0.00025 & VITSGYA & \\
\hline 6 & Uncharacterized protein & 52.22 & 0.00028 & VITSYQ & \\
\hline 7 & Uncharacterized protein & 52.08 & 0.00032 & VLTSQY & \\
\hline 8 & Uncharacterized protein & 47.46 & 0.001 & HDGTFISSIGD & \\
\hline 9 & Uncharacterized protein & 47.23 & 0.0011 & ETSGTSSRVR & Glu- > pyro-Glu (N-term E) \\
\hline 10 & SJCHGC05429 protein & 44.74 & 0.0019 & VSFITLFM & Oxidation (M) \\
\hline 11 & Dynein heavy chain 1 cytosolic & 44.03 & 0.0022 & IFNIEPIRAKV & \\
\hline 12 & SOSS complex subunit B1 & 43.75 & 0.0022 & AGDSSSTNR & \\
\hline 13 & Vigilin & 43.24 & 0.003 & GRGGSKLTELLEGYKRVQV & \\
\hline 14 & Uncharacterized protein & 42.6 & 0.0027 & LEQENRH & \\
\hline 15 & Uncharacterized protein & 42.6 & 0.0027 & LEQEEYD & \\
\hline 16 & Serine/threonine-protein kinase SIK3 & 42.45 & 0.0028 & PSIPASNNN & \\
\hline 17 & Putative helix-loop-helix zipper protein & 41.88 & 0.0034 & SSNTSSNPT & \\
\hline 18 & Rho GTPase-activating protein 35 & 41.81 & 0.0039 & SAFSAPNHS & \\
\hline 19 & Helicase & 41.29 & 0.0043 & DVGLITGDIKVAPD & \\
\hline 20 & Uncharacterized protein & 41.24 & 0.015 & $\begin{array}{l}\text { SPIKKEEVPAGFSPSE } \\
\text { YHLIKKMRDILR }\end{array}$ & Oxidation (M) \\
\hline
\end{tabular}


Table 2. Cont.

\begin{tabular}{|c|c|c|c|c|c|}
\hline No. & Precursor Protein & Score & E-Value & Peptide & Modification \\
\hline \multicolumn{6}{|c|}{ D28 } \\
\hline 1 & Uncharacterized protein & 74.43 & $2.6 \mathrm{E}-06$ & $\begin{array}{l}\text { QWANLMEKIQASVA } \\
\text { TNPIITPVAQENQ }\end{array}$ & $\begin{array}{l}\text { Gln- > pyro-Glu (N-term } \\
\text { Q); Oxidation (M) }\end{array}$ \\
\hline 2 & Putative glycosyltransferase & 60.49 & 0.000051 & IDVMPSIKTPIE & \\
\hline 3 & Putative actin & 56.38 & 0.00013 & VFPSIVGRPR & \\
\hline 4 & Bifunctional protein NCOAT & 52.25 & 0.00034 & NSVAVTLEDL & \\
\hline 5 & Putative DNA polymerase delta small subunit & 51.8 & 0.00039 & FAGSGQVKPGHSM & \\
\hline 6 & Glycosyltransferase 14 family member & 50.1 & 0.00091 & TKRQEFF & \\
\hline 7 & Uncharacterized protein & 45.94 & 0.0013 & THTLTLEN & \\
\hline 8 & Coiled-coil domain-containing protein 170 & 45.9 & 0.0014 & EYVRHNEK & Glu- > pyro-Glu (N-term E) \\
\hline 9 & Coiled-coil domain-containing protein 81 & 45.14 & 0.0018 & EIIFNDIGKLRI & Glu- > pyro-Glu (N-term E) \\
\hline 10 & Uncharacterized protein & 44.23 & 0.002 & THVDIDKT & \\
\hline 11 & Putative multidrug resistance protein $1,2,3$ & 44.09 & 0.0022 & QSRANLVTGIIALL & \\
\hline 12 & Uncharacterized protein & 44.02 & 0.0044 & CLSVMQII & \\
\hline 13 & Pogo transposable element with ZNF domain & 42.73 & 0.0036 & NIENLDCLECGKCMGD & \\
\hline 14 & Putative organic solute transporter & 42.32 & 0.0031 & KQATLQFCV & \\
\hline 15 & Protein kinase & 42.08 & 0.0037 & TEPTIKRMLAENVS & Oxidation (M) \\
\hline 16 & Uncharacterized protein & 41.47 & 0.0041 & SRQAVQTMGSLFQ & Oxidation (M) \\
\hline 17 & Actin bundling/missing in metastasis-related & 41.18 & 0.0045 & TTVVSNNGI & \\
\hline 18 & $\begin{array}{l}\text { Putative Family with sequence similarity } 98, \\
\text { member A }\end{array}$ & 40.69 & 0.0049 & GISDRQWS & \\
\hline 19 & Nuclear factor 1 C-type & 40.67 & 0.008 & LAKENSFF & \\
\hline 20 & Uncharacterized protein & 40.4 & 0.0051 & SRQAVQTMGSLF & Oxidation (M) \\
\hline \multicolumn{6}{|c|}{ D56 } \\
\hline 1 & Uncharacterized protein & 60.61 & 0.000054 & NEVHTMLGQSTEEIRA & Oxidation (M) \\
\hline 2 & Putative organic solute transporter & 51.52 & 0.00037 & KQATLQFCV & \\
\hline 3 & Uncharacterized protein & 49.52 & 0.00067 & LPFLQELDSDQILR & \\
\hline 4 & $\begin{array}{c}\text { Voltage-dependent calcium channel } \\
\text { OS }=\begin{array}{c}\text { Schistosoma mansoni GN }=\text { Smp_197640 } \\
\text { PE }=4 \text { SV = } 1\end{array}\end{array}$ & 49.14 & 0.0037 & TTSSPLTLIL & \\
\hline 5 & Putative importin-beta 2 & 46.95 & 0.0015 & MLMPPLFEKWNAL & \\
\hline 6 & Uncharacterized protein & 46.95 & 0.0011 & YDEGKIGIFI & \\
\hline 7 & Zinc finger MIZ domain-containing protein 1 & 46.95 & 0.0015 & PFKCEQPPNGCADAL & \\
\hline 8 & $\begin{array}{l}\text { Complement component } 1 \mathrm{Q} \\
\text { subcomponent-binding protein, mitochondrial }\end{array}$ & 45.48 & 0.0016 & EAHPDLRI & Glu- > pyro-Glu (N-term E) \\
\hline 9 & 39 S ribosomal protein $\mathrm{L} 46$, mitochondrial & 45.03 & 0.0018 & RTRSGVNIFPI & \\
\hline 10 & Uncharacterized protein & 44.96 & 0.003 & LQLMVPV & \\
\hline 11 & Proteasome $26 \mathrm{~S}$ subunit subunit 4 ATPase & 44.88 & 0.0018 & LSFVDKGMLE & Oxidation (M) \\
\hline 12 & Uncharacterized protein & 44.71 & 0.002 & SVATNPIITPVAQENQ & \\
\hline 13 & Teneurin-2 & 44.14 & 0.0024 & ISILILAFLLAL & \\
\hline 14 & Protein kinase & 43.75 & 0.0024 & TQCIAYAAGY & \\
\hline 15 & Tyrosine-protein kinase Abl & 43.57 & 0.0025 & IEAEVALELEKQP & \\
\hline 16 & Uncharacterized protein & 42.4 & 0.0056 & LEEKMLM & 2 Oxidation $(\mathrm{M})$ \\
\hline 17 & Protein kinase & 42.05 & 0.0037 & TEPTIKRMLAENVS & Oxidation (M) \\
\hline 18 & Rhabdoid tumor deletion region protein 1 & 41.97 & 0.0047 & TTNHGRYTTLNAGAI & \\
\hline 19 & Cadherin-related tumor suppressor & 41.64 & 0.0038 & MMLSNDLIDS & Oxidation (M) \\
\hline 20 & Uncharacterized protein & 40.32 & 0.0048 & LTMNTEL & Oxidation (M) \\
\hline
\end{tabular}


Table 3. The identified peptide sequences of $S$. mekongi ubiquitin thioesterase trabid from 14,28 , and 56 days after infection.

\begin{tabular}{|c|c|c|c|}
\hline Sequence & Score & E-Value & Modification \\
\hline \multicolumn{4}{|c|}{ Day 14} \\
\hline SSNESTADINQTTG * & 36.65 & 0.012 & \\
\hline TSYSPYASPRSSSR * & 21.27 & $4.40 \times 10^{-1}$ & \\
\hline TYTQMPSTNIPLSTPSE * & 28.91 & 0.079 & Oxidation (M) \\
\hline KLSSPLTGNQIHPALQLVFN * & 20.94 & 1.30 & \\
\hline \multicolumn{4}{|c|}{ Day 28} \\
\hline HSTLPV & 11.45 & 3.10 & \\
\hline DGGAKWPCGV * & 39 & 0.0073 & \\
\hline SSNESTADINQTTG * & 32.69 & 0.031 & \\
\hline \multicolumn{4}{|c|}{ Day 56} \\
\hline DGGAKWPCGV * & 34.35 & 0.021 & \\
\hline VMCFASSPQPLC * & 24.27 & $2.10 \times 10^{-1}$ & Oxidation (M) \\
\hline ESPLTSCGGTTLPV * & 26.69 & $1.20 \times 10^{-1}$ & Glu- > pyro-Glu (N-term E) \\
\hline
\end{tabular}

Table 4. Percent identity matrix of S. mekongi, S. japonicum, S. mansoni, S. haematobium, M. musculus and Homo sapiens ubiquitin thioesterase trabid.

\begin{tabular}{ccccc}
\hline & S. mekongi & S. japonicum & S. mansoni & S. haematobium \\
\hline S. mekongi & 100 & 93.24 & 81.49 & 81.12 \\
\hline S. japonicum & 93.24 & 100 & 82.02 & 81.66 \\
\hline S. mansoni & 81.49 & 82.02 & 100 & 94.86 \\
\hline S. haematobium & 81.12 & 81.66 & 94.86 & 100 \\
\hline O. felineus & 55.13 & 54.77 & 56.23 & 56.12 \\
\hline C. sinensis & 54.89 & 54.53 & 55.87 & 55.65 \\
\hline O. viverrini & 54.89 & 54.18 & 55.87 & 55.53 \\
\hline M. musculus & 42.70 & 42.70 & 42.25 & 42.51 \\
\hline H. sapiens & 39.52 & 39.84 & 40.22 & 40.06 \\
\hline
\end{tabular}

\section{Discussion}

In silico transcriptome mining is a powerful tool for peptidome prediction from biological samples. Using homology-based searches and simple bioinformatics workflows, large peptidomes have recently been predicted for a variety of organisms [14]. However, the mining approach cannot identify peptides produced from post-translational processing. The precursor proteins of processed peptides cannot be identified via the mining technique. Furthermore, the relationships between mRNA and peptide levels are complex and strongly influenced by post-transcriptional and post-translational regulatory mechanisms. Mass spectrometry-based peptidomic approaches are powerful techniques for peptide discovery. This approach can identify peptides derived from proteasome-mediated cleavage of intracellular proteins within the cell [15]. Numerous bioactive peptides requiring proteasome activity for their production are present in tissues and cells [16-18]. While the mass spectrometry approach is powerful, peptides at low abundance can be difficult to identify using this approach. Additionally, peptides with extensive post-translational modifications do not effectively ionize, leading to loss of detection [19]. In contrast, in silico transcriptome mining with subsequent bioinformatic peptide prediction is not lim- 
ited by the above factors. Accordingly, this study used complementary mining and mass spectrometry approaches for S. mekongi peptide discovery.

Classical neurotransmitters such as acetylcholine, serotonin and catecholamines have been studied in parasitic platyhelminths and proposed as targets for anthelmintic drugs [20]. However, few studies have addressed the importance of neuropeptides in platyhelminths. In this study, YGGW-amide related peptides were a major S. mekongi neuropeptide family identified using a mining approach. Limited information is available on this peptide family in schistosomes. However, this family has been described in C. elegans. These peptides are expressed in chemosensory neurons, head neurons, spermatheca, hypoderm, intestine, and embryos of $C$. elegans [21]. Using mass spectrometry approaches, VSTGGG peptides belonging to the YGGW-amide related peptide family were identified in S. mekongi adult worms; precursor proteins containing GGG related regions were identified in both S. mekongi adult worms and eggs. In C. elegans, GGG related peptides are also abundant and are localized in chemosensory neurons, sensory neurons, head neurons, tail neurons, the ventral nerve cord, spermatheca, vulval muscles, and intestine [22].

An important neuropeptide class in flatworms is formed by the FMRFamide-like peptides [23]. Using the in silico transcriptome mining approach, 74 S. mekongi FMRFamide-like peptides were identified. Neuropeptides of this family are typically less than 20 amino acids in length and contain an RFamide motif at their C-terminus. FMRFamide-like peptides play a central role in parasite neuromuscular biology. In S. mansoni, FMRFamide-like peptides are widespread throughout the nervous system and produce potent myoexcitation [24]. The alteration of levels of $C$. elegans FMRFamide-like peptide signaling impacted locomotory and reproductive behavior. These peptides can bind multiple receptors, making it difficult to indicate the specific receptor being activated by FMRFamide-like peptides [25]. The YIRFamide related peptide is a member of the FMRFamide-like peptide family. It activates muscle contraction by enhancing $\mathrm{Ca}^{2+}$ influx through sarcolemmal voltage operated $\mathrm{Ca}^{2+}$ channels (VOCCs). VOCC inhibitors such as nicardipine, verapamil, and methoxyverapamil could inhibit these contractions [26]. YIRFamide related peptides have also been identified in Dugesia tigrina [27] and Bdelloura candida [28]. In our study, the GYIRF related peptide was detected in S. mekongi adult worms but was not observed in eggs. This finding supported the possibility that FMRFamide-like peptides play important roles in S. mekongi locomotion. Inhibition of FMRFamide-like peptide receptors might be a practical approach to treat $S$. mekongi infection.

Seven precursor sequences of molluscan ELH were identified in S. mekongi using the transcriptome mining approach. ELH is a member of the neuropeptide F family. Peptides in this family are approximately 40 amino acids in length and are characterized by an RxRFamide sequence at the C-terminus. These peptides are orthologs of the neuropeptide $\mathrm{Y}$ family in vertebrates. The neuropeptide $\mathrm{F}$ and $\mathrm{Y}$ families demonstrate high similarity in terms of structure and function [29]. The IRIRFH, DRIRFH and HRIRFN related peptides were detected in S. mekongi. In S. mansoni, DRIRFH and HRIRFN related peptides were reported. S. mansoni ELH potently inhibits Forskolin stimulation of cyclic AMP accumulation, leading to downstream signaling pathway regulation [30]. In C. elegans, introduction of a defective mutant ELH into wild-type hermaphrodites or females induced an egg-laying defective phenotype [31]. Additionally, ELH could stimulate ovulation in gastropods, including Aplysia californica and Lymnaea stagnalis [32]. The S. mekongi ELH may also play an important role in regulation of egg-laying.

The protein precursor of GFVRI related peptides (Supplementary Dataset 1: comp7372_ seq0, Q5DC41) was identified in S. mekongi using the transcriptome mining approach. The GFVRI amide related peptides are a novel family of bioactive helminth neuropeptides that were first reported in S. mansoni. Treatment of S. mansoni adult worms with this peptide led to significant mobility inhibition [33]. This neuropeptide family might mediate the movement of schistosomal worms.

Both mining and mass spectrometry approaches identified the precursor proteins of PLG related peptides in S. mekongi adult worms and eggs. PLG related peptides are part of 
the vasopressin/oxytocin peptide family. The QVLMPLGYKVISR peptide was identified from S. mekongi eggs by mass spectrometry. Vasopressin and oxytocin are neuropeptide hormones. Vasopressinis mainly regulate fluid homeostasis and blood pressure [34]. Oxytocin is involved in uterine contractions and induces milk ejection [35]. Both peptides modulate social behavior, memory, and learning. In Hirudo medicinalis, CFIRNCPLG-NH $\mathrm{H}_{2}$ has been reported as vasopressin/oxytocin peptide family involved in reproductive behavior [7] This peptide family may be important for $S$. mekongi reproduction.

Kisspeptins are ligands of G-protein coupled receptors. Kisspeptins could initiate signaling associated with secretion of gonadotropin-releasing hormone in humans [36]. A total of $26 \mathrm{KiSS1}$ precursor sequences were identified from S. mekongi adult worms using the transcriptome mining approach. In the sea cucumber Apostichopus japonicas, KiSS1 neuropeptides play roles in triggering rapid intracellular mobilization of $\mathrm{Ca}^{2+}$ and are closely related to seasonal reproduction and metabolism [37]. KiSS1 has been described in teleosts such as the sea bass. The receptors of KiSS1 peptides are mainly expressed in the brain and gonads of sea bass, medaka, and zebrafish. Expression levels of kisspeptins and KiSS receptors in the sea bass testis varied significantly throughout the reproductive cycle [38]. Therefore, KiSS1 neuropeptides may be involved in the reproduction of S. mekongi.

Eleven precursor sequences of $S$. mekongi arthropod CHH/MIH/GIH/VIH hormone peptides were detected using the transcriptome mining approach. In crustaceans, the crustacean hyperglycemic hormone (CHH)-family, vitellogenesis-inhibiting hormone (VIH), also known as gonad-inhibiting hormone $(\mathrm{GIH})$, play roles in vitellogenesis [39]. Moreover, $\mathrm{MIH}$ is a key endocrine regulator that regulates Callinectes sapidus molting and reproduction [40]. The S. mekongi arthropod $\mathrm{CHH} / \mathrm{MIH} / \mathrm{GIH} / \mathrm{VIH}$ hormone family may have functions in reproduction and development.

The EHP, QHL and QHP related peptides are significant TRH domains and were identified in S. mekongi using both transcriptome mining and mass spectrometry approaches. The EAAVVSRQHPVKGEC and QHLSMNPLVESF peptides were identified by mass spectrometry in S. mekongi adult worms and eggs, respectively. TRH influences the release of other hormones, including prolactin, growth hormone, vasopressin, insulin, and the neurotransmitters noradrenaline and adrenaline [41]. TRH orthologs were identified in the annelid Platynereis dumerilii as well as in C. elegans [42]. In C. elegans, TRH related peptide is required for growth in body size [43]. Similar to other worms, the TRH family may be involved in S. mekongi growth and development.

The precursor sequences of TKP related peptides were dominantly identified in S. mekongi adult worms. A total of 178 sequences were identified by transcriptome mining while five and two sequences were detected in S. mekongi adult worms and eggs, respectively, by mass spectrometry. The TKP related peptides are part of the N/A neuropeptide family. In humans, these peptides could inhibit macrophage/microglial activation via an unknown mechanism [44]. In mice, TKP related peptides are inhibitors of microglial activation [45]. The role of this peptide in S. mekongi adult worms may involve host immune escape through macrophage inhibition.

Although, the peptides identified in this study may influence several behaviors in S. mekongi. However, there is a lack of confirmation of the functional information on these peptides. The antioxidant, antimicrobial and other properties of these peptides were not evaluated in this study. Further investigations should be performed to confirm the role of each peptide in S. mekongi.

S. mekongi infection is currently diagnosed by detection of parasite eggs in stool specimens. It is a low-sensitivity technique, which can underestimate the prevalence and affect mass drug administration. Antibody detection in blood samples is also used to indicate the infection. However, the crude antigen needs to be prepared from the worm or egg which shows variation from batch to batch. Identification of circulating proteins or peptides could improve the diagnosis. The production of monoclonal antibody which binds to these antigens could be one of the strategies for $S$. mekongi diagnosis development. The $S$. mekong $i$ peptide profiles in mouse serum 14, 28, and 56 days after infection were dissimilar. This 
result is consistent with the life cycle of S. mekongi. Approximately 14 days after infection, some $S$. mekong $i$ worms are in the immature stage. They further develop to the mature adult stage and undergo pairing 28 days after infection. Eggs can be observed 56 days after infection. The SQFQPHFVVDTMSKGA, QWANLMEKIQASVATNPIITPVAQENQ, and NEVHTMLGQSTEEIRA peptides had the highest scores 14, 28, and 56 days after infection, respectively. This result could be useful to detect the early, middle, and late stages of $S$. mekongi infection. Eight unique peptides of the $S$. mekongi ubiquitin thioesterase trabid were identified in infected mouse sera starting from 14 days after infection. Comparison of the $S$. mekongi ubiquitin thioesterase trabid protein sequence with homologs from S. japonicum, S. mansoni, S. haematobium, mouse, and human showed that this protein was conserved among schistosoma species. In Drosophila melanogaster, the ubiquitin thioesterase trabid is a positive regulator of the Wnt signaling pathway. This pathway regulates numerous processes associated with cell development [46]. In humans, hyperactivation of the Wnt pathway causes colorectal tumors [47]. The S. mekongi ubiquitin thioesterase trabid may play roles in growth and development. The protein may be a potential target for early diagnosis of schistosomiasis. However, the individual serum analysis of infected mice needs to be further validated for further diagnosis application.

\section{Conclusions}

Identification of low molecular weight proteins and peptides from S. mekongi worm, egg, and infected mouse sera provided the information insight into the molecular biology of schistosome. Besides, the findings could be useful for further schistosomal drug and diagnostic development.

Supplementary Materials: The following are available online at https:/ /www.mdpi.com/article/10 .3390/biom11040559/s1, Table S1: Identification of S. meknogi adult worm peptidome using mining approach, Table S2: Identification of S. mekongi worm, egg and infected serum peptidomes using proteomics, Table S3: Top-10 S. mekongi peptides in adult worm and egg ranked by peptide score, Table S4: The amino acid position of neuropeptide on their precursor protein sequence of S. mekongi adult worm, Table S5: The amino acid position of neuropeptide on their precursor protein sequence of $S$. mekongi adult egg.

Author Contributions: All authors participated in the design, interpretation and analysis of the study; T.T., P.A., N.S. and O.R. conducted and analyzed the peptidomic experiments; Y.L., P.C., Y.C. maintained parasite life cycle; T.T. and O.R. performed bioinformatics analysis; all authors wrote, revised and approved the final manuscript. All authors have read and agreed to the published version of the manuscript.

Funding: This research was funded by the Faculty of Tropical Medicine, Mahidol University, ICTM grant and the Agricultural Research Development Agency, grant year 2564.

Conflicts of Interest: The authors declare no competing interests.

\section{References}

1. Muth, S.; Sayasone, S.; Odermatt-Biays, S.; Phompida, S.; Duong, S.; Odermatt, P. Schistosoma mekongi in Cambodia and Lao People's Democratic Republic. Adv. Parasitol. 2010, 72, 179-203. [PubMed]

2. World Health Organization. Meeting Report. In: Expert Consultation to Accelerate Elimination of Asian Schistosomiasis. 2017. Available online: https:/ /apps.who.int/iris/handle/10665/259630 (accessed on 17 February 2021).

3. Wittes, R.; MacLean, J.D.; Law, C.; Lough, J.O. Three Cases of Schistosomiasis Mekongi from Northern Laos. Am. J. Trop. Med. Hyg. 1984, 33, 1159-1165. [CrossRef] [PubMed]

4. Van Bael, S.; Watteyne, J.; Boonen, K.; De Haes, W.; Menschaert, G.; Ringstad, N.; Horvitz, H.R.; Schoofs, L.; Husson, S.J.; Temmerman, L. Mass spectrometric evidence for neuropeptide-amidating enzymes in Caenorhabditis elegans. J. Biol. Chem. 2018, 293, 6052-6063. [CrossRef] [PubMed]

5. Yew, J.Y.; Kutz, K.K.; Dikler, S.; Messinger, L.; Li, L.; Stretton, A.O. Mass spectrometric map of neuropeptide expression in Ascaris suum. J. Comp. Neurol. 2005, 488, 396-413. [CrossRef] [PubMed]

6. Quinn, G.A.; Heymans, R.; Rondaj, F.; Shaw, C.; de Jong-Brink, M. Schistosoma mansoni dermaseptin-like peptide: Structural and functional characterization. J. Parasitol. 2005, 91, 1340-1351. [CrossRef] [PubMed] 
7. McVeigh, P.; Mair, G.R.; Novozhilova, E.; Day, A.; Zamanian, M.; Marks, N.J.; Kimber, M.J.; Day, T.A.; Maule, A.G. Schistosome I/Lamides-A new family of bioactive helminth neuropeptides. Int. J. Parasitol. 2011, 41, 905-913. [CrossRef] [PubMed]

8. Collins, J.J., 3rd; Hou, X.; Romanova, E.V.; Lambrus, B.G.; Miller, C.M.; Saberi, A.; Sweedler, J.V.; Newmark, P.A. Genome-wide analyses reveal a role for peptide hormones in planarian germline development. PLoS Biol. 2010, 8, e1000509. [CrossRef] [PubMed]

9. Balog, C.I.; Alexandrov, T.; Derks, R.J.; Hensbergen, P.J.; van Dam, G.J.; Tukahebwa, E.M.; Kabatereine, N.B.; Thiele, H.; Vennervald, B.J.; Mayboroda, O.A.; et al. The feasibility of MS and advanced data processing for monitoring Schistosoma mansoni infection. Proteom. Clin. Appl. 2010, 4, 499-510. [CrossRef] [PubMed]

10. Balog, C.I.; Hensbergen, P.J.; Derks, R.; Verweij, J.J.; Van Dam, G.J.; Vennervald, B.J.; Deelder, A.M.; Mayboroda, O.A. Novel Automated Biomarker Discovery Work Flow for Urinary Peptidomics. Clin. Chem. 2009, 55, 117-125. [CrossRef] [PubMed]

11. Phuphisut, O.; Ajawatanawong, P.; Limpanont, Y.; Reamtong, O.; Nuamtanong, S.; Ampawong, S.; Chaimon, S.; Dekumyoy, P.; Watthanakulpanich, D.; Swierczewski, B.E.; et al. Transcriptomic analysis of male and female Schistosoma mekongi adult worms. Parasites Vectors 2018, 11, 504. [CrossRef] [PubMed]

12. Wang, Y.; Wang, M.; Yin, S.; Jang, R.; Wang, J.; Xue, Z.; Xu, T. NeuroPep: A comprehensive resource of neuropeptides. Database 2015, 2015, bav038. [CrossRef] [PubMed]

13. Mooney, C.; Haslam, N.J.; Pollastri, G.; Shields, D.C. Towards the Improved Discovery and Design of Functional Peptides: Common Features of Diverse Classes Permit Generalized Prediction of Bioactivity. PLoS ONE 2012, 7, e45012. [CrossRef] [PubMed]

14. Christie, A.E.; Roncalli, V.; Cieslak, M.C.; Pascual, M.G.; Yu, A.; Lameyer, T.J.; Stanhope, M.E.; Dickinson, P. Prediction of a neuropeptidome for the eyestalk ganglia of the lobster Homarus americanus using a tissue-specific de novo assembled transcriptome. Gen. Comp. Endocrinol. 2017, 243, 96-119. [CrossRef] [PubMed]

15. Ferro, E.S.; Rioli, V.; Castro, L.M.; Fricker, L.D. Intracellular peptides: From discovery to function. EuPA Open Proteomics 2014, 3 , 143-151. [CrossRef]

16. Gelman, J.S.; Sironi, J.; Castro, L.M.; Ferro, E.S.; Fricker, L.D. Peptidomic Analysis of Human Cell Lines. J. Proteome Res. 2011, 10, 1583-1592. [CrossRef] [PubMed]

17. Fricker, L.D. Analysis of mouse brain peptides using mass spectrometry-based peptidomics: Implications for novel functions ranging from non-classical neuropeptides to microproteins. Mol. BioSyst. 2010, 6, 1355-1365. [CrossRef] [PubMed]

18. Fricker, L.D.; Gelman, J.S.; Castro, L.M.; Gozzo, F.C.; Ferro, E.S. Peptidomic Analysis of HEK293T Cells: Effect of the Proteasome Inhibitor Epoxomicin on Intracellular Peptides. J. Proteome Res. 2012, 11, 1981-1990. [CrossRef] [PubMed]

19. ChristieElizabeth, A.E.; Stemmler, E.A.; Dickinson, P.S. Crustacean neuropeptides. Cell. Mol. Life Sci. 2010, 67, 4135-4169. [CrossRef]

20. Chance, M.R.A.; Mansour, T.E. A Contribution to the Pharmacology Of Movement in the Liver Fluke. Br. J. Pharmacol. Chemother. 1953, 8, 134-138. [CrossRef] [PubMed]

21. Brownlee, D.; Fairweather, I.; Holden-Dye, L.; Walker, R. Nematode neuropeptides: Localization, isolation and functions. Parasitol. Today 1996, 12, 343-351. [CrossRef]

22. Bargmann, C.I.; Horvitz, H.R. Control of larval development by chemosensory neurons in Caenorhabditis elegans. Science 1991, 251, 1243-1246. [CrossRef] [PubMed]

23. Halton, D.W.; Maule, A.G. Flatworm nerve-muscle: Structural and functional analysis. Can. J. Zool. 2004, 82, 316-333. [CrossRef]

24. Day, T.A.; Maule, A.G.; Shaw, C.; Pax, R.A. Structure-Activity Relationships of FMRFamide-Related Peptides Contracting Schistosoma mansoni Muscle. Peptides 1997, 18, 917-921. [CrossRef]

25. Chang, Y.J.; Burton, T.; Ha, L.; Huang, Z.; Olajubelo, A.; Li, C. Modulation of Locomotion and Reproduction by FLP Neuropeptides in the Nematode Caenorhabditis elegans. PLoS ONE 2015, 10, e0135164. [CrossRef] [PubMed]

26. Novozhilova, E.; Kimber, M.J.; Qian, H.; McVeigh, P.; Robertson, A.P.; Zamanian, M.; Maule, A.G.; Day, T.A. FMRFamide-Like Peptides (FLPs) Enhance Voltage-Gated Calcium Currents to Elicit Muscle Contraction in the Human Parasite Schistosoma mansoni. PLoS Negl. Trop. Dis. 2010, 4, e790. [CrossRef] [PubMed]

27. Johnston, R.; Shaw, C.; Halton, D.; Verhaert, P.; Baguña, J. GYIRFamide: A Novel FMRFAmide-Related Peptide (FaRP) from the Triclad Turbellarian, Dugesia tigrina. Biochem. Biophys. Res. Commun. 1995, 209, 689-697. [CrossRef]

28. Johnston, R.N.; Shaw, C.; Halton, D.W.; Verhaert, P.; Blair, K.L.; Brennan, G.P.; Price, D.A.; Anderson, P.A.V. Isolation, Localization, and Bioactivity of the FMRFamide-Related Neuropeptides GYIRFamide and YIRFamide from the Marine Turbellarian Bdelloura candida. J. Neurochem. 2002, 67, 814-821. [CrossRef]

29. Nathoo, A.N.; Moeller, R.A.; Westlund, B.A.; Hart, A.C. Identification of neuropeptide-like protein gene families in Caenorhabditis elegans and other species. Proc. Natl. Acad. Sci. USA 2001, 98, 14000-14005. [CrossRef] [PubMed]

30. Humphries, J.E.; Kimber, M.J.; Barton, Y.-W.; Hsu, W.; Marks, N.J.; Greer, B.; Harriott, P.; Maule, A.G.; Day, T.A. Structure and Bioactivity of Neuropeptide F from the Human Parasites Schistosoma mansoni and Schistosoma japonicum. J. Biol. Chem. 2004, 279, 39880-39885. [CrossRef]

31. McGovern, M.; Yu, L.; Kosinski, M.; Greenstein, D.; Savage-Dunn, C. A role for sperm in regulation of egg-laying in the Nematode C. elegans. BMC Dev. Biol. 2007, 7, 41. [CrossRef] [PubMed] 
32. Nuurai, P.; Engsusophon, A.; Poomtong, T.; Sretarugsa, P.; Hanna, P.; Sobhon, P.; Wanichanon, C. Stimulatory Effects of EggLaying Hormone and Gonadotropin-Releasing Hormone on Reproduction of the Tropical Abalone, Haliotis asinine Linnaeus. J. Shellfish Res. 2010, 29, 627-635. [CrossRef]

33. McCormick, S.D.; Bradshaw, D. Hormonal control of salt and water balance in vertebrates. Gen. Comp. Endocrinol. 2006, 147, 3-8. [CrossRef]

34. Gimpl, G.; Fahrenholz, F. The Oxytocin Receptor System: Structure, Function, and Regulation. Physiol. Rev. 2001, 81, 629-683. [CrossRef] [PubMed]

35. Beets, I.; Temmerman, L.; Janssen, T.; Schoofs, L. Ancient neuromodulation by vasopressin/oxytocin-related peptides. Worm 2013, 2, e24246. [CrossRef]

36. Skorupskaite, K.; George, J.T.; Anderson, R.A. The kisspeptin-GnRH pathway in human reproductive health and disease. Hum. Reprod. Update 2014, 20, 485-500. [CrossRef]

37. Wang, T.; Cao, Z.; Shen, Z.; Yang, J.; Chen, X.; Yang, Z.; Xu, K.; Xiang, X.; Yu, Q.; Song, Y.; et al. Existence and functions of a kisspeptin neuro-peptide signaling system in a non-chordate deuterostome species. Elife 2020, 9, e53370. [CrossRef]

38. Felip, A.; Espigares, F.; Zanuy, S.; Gomez, A. Differential activation of kiss receptors by Kiss1 and Kiss2 peptides in the sea bass. Reproduction 2015, 150, 227-243. [CrossRef] [PubMed]

39. Jayasankar, V.; Tomy, S.; Wilder, M.N. Insights on Molecular Mechanisms of Ovarian Development in Decapod Crustacea: Focus on Vitellogenesis-Stimulating Factors and Pathways. Front. Endocrinol. 2020, 11, 577925. [CrossRef]

40. Zmora, N.; Trant, J.; Zohar, Y.; Chung, J.S. Molt-inhibiting hormone stimulates vitellogenesis at advanced ovarian developmental stages in the female blue crab, Callinectes sapidus 1: An ovarian stage dependent involvement. Saline Syst. 2009, 5, 7. [CrossRef]

41. Griffiths, E.C. Thyrotrophin releasing hormone: Endocrine and central effects. Psychoneuroendocrinology 1985, 10, 225-235. [CrossRef]

42. Jékely, G. Global view of the evolution and diversity of metazoan neuropeptide signaling. Proc. Natl. Acad. Sci. USA 2013, 110, 8702-8707. [CrossRef]

43. Van Sinay, E.; Mirabeau, O.; Depuydt, G.; Van Hiel, M.B.; Peymen, K.; Watteyne, J.; Zels, S.; Schoofs, L.; Beets, I. Evolutionarily conserved TRH neuropeptide pathway regulates growth in Caenorhabditis elegans. Proc. Natl. Acad. Sci. USA 2017, 114, E4065-E4074. [CrossRef] [PubMed]

44. Bhasin, M.; Wu, M.; Tsirka, S.E. Modulation of microglial/macrophage activation by macrophage inhibitory factor (TKP) or tuftsin (TKPR) attenuates the disease course of experimental autoimmune encephalomyelitis. BMC Immunol. 2007, 8, 10. [CrossRef]

45. Rogove, A.; Tsirka, S. Neurotoxic responses by microglia elicited by excitotoxic injury in the mouse hippocampus. Curr. Biol. 1998, 8, 19-25. [CrossRef]

46. Tran, H.; Hamada, F.; Schwarz-Romond, T.; Bienz, M. Trabid, a new positive regulator of Wnt-induced transcription with preference for binding and cleaving K63-linked ubiquitin chains. Genes Dev. 2008, 22, 528-542. [CrossRef]

47. Bienz, M.; Clevers, H. Linking Colorectal Cancer to Wnt Signaling. Cell 2000, 103, 311-320. [CrossRef] 